\title{
Efeitos do aumento da idade mínima legal no trabalho dos brasileiros de 14 e 15 anos
}

\author{
Andrea Rodrigues Ferro ${ }^{1}$
}

Ana Lúcia Kassouf ${ }^{2}$

Resumo: O objetivo deste trabalho é verificar o efeito que o aumento da idade mínima legal para ingresso no mercado de trabalho no Brasil teve na oferta de trabalho dos adolescentes de 14 e 15 anos de idade, que em 1998 passou de 14 para 16 anos para o trabalho formal e de 12 para 14 anos na condição de aprendiz. São realizadas análises de freqüência e econométrica mais complexa dos dados das PNADs de 1995 a 2003. Por meio da análise de freqüência dos dados, nota-se um declínio na proporção de meninos e meninas de 14 e 15 anos que trabalham, tanto na área urbana quanto na área rural, mas não é possível separar o efeito em legislação e tendência. Nota-se também que neste período houve aumento na proporção de adolescentes que freqüentam a escola e diminuição nos salários dos adolescentes que trabalham e na renda per capita média das famílias com adolescentes trabalhando ou não. Como conseqüência do aumento da freqüência à escola, nota-se ainda um aumento na proporção de adolescentes trabalhando menos de 40 horas semanais e uma redução na dos que trabalham mais de 40 horas por semana. Na análise econométrica estimou-se um modelo probit agregando-se os dados das PNADs de 1995 a 2003 (pooling). O coeficiente da variável de interesse,

\footnotetext{
${ }^{1}$ Aluna do Programa de Pós-Graduação em Economia Aplicada - ESALQ/USP. Bolsista do CNPq e pesquisadora do CEPEA. E-mail: arferro@esalq.usp.br

${ }^{2}$ Professora do Departamento de Economia, Administração e Sociologia - ESALQ/USP e pesquisadora do CEPEA. E-mail: alkassou@esalq.usp.br
} 
que capta o efeito da mudança da lei, mostrou-se estatisticamente significativo nas equações de trabalho de meninos e meninas da área urbana e rural. Conclui-se então que a legislação contribuiu significativamente para uma redução na porcentagem de adolescentes no mercado de trabalho, embora não tenha eliminado completamente o trabalho infantil.

Palavras chave: idade mínima para trabalhar; trabalho de adolescentes; mudança na legislação; avaliação de políticas públicas.

Classificação JEL: J 48 (Public Policy)

Abstract: In 1998 the child labor legislation was amended restricting the employment to minors under sixteen instead of fourteen. Using data from household surveys (PNAD) it is possible to observe a decline in the percentage of 14 and 15 year-old children working in the decades. This paper examines whether a federal law restricting the employment of child labor contributed to this decline. Using a probit model and pooling the cross-sectional data from 1995 to 2003, we observe statistically significant coefficients for the variable representing the change in the legislation for boys and girls in the urban and rural areas. Therefore, it can be inferred that the legislation contributed to a decrease in the percentage of teenagers working in the labor market, although it did not eliminate child labor.

Key words: minimum age to work; teenager work; change in the legislation; public policy evaluation.

JEL Classification: J 48 (Public Policy)

\section{Introdução}

A Organização Internacional do Trabalho (OIT) considera criança o indivíduo com 15 anos ou menos, e a criança é considerada trabalhadora se faz parte da população economicamente ativa, independentemente de estar trabalhando ou procurando emprego (Jafarey \& Lahiri, 2001). Entretanto, a definição de criança difere entre os países e muitos ainda 
não ratificaram a Convenção $n^{\circ} 138$ e a Resolução $n^{0}$ 146, que tratam dos direitos das crianças, principalmente das que exercem algum tipo de atividade laboral, no intuito de erradicar o trabalho infantil como definido anteriormente.

No Brasil, que é um país-membro da OIT, a legislação trata como criança o indivíduo com até 12 anos, e como adolescentes os que têm entre 12 e 18 anos de idade. De acordo com a Constituição de 1988, a idade mínima para ingresso no mercado de trabalho era de 14 anos, permitindo-se o ingresso de indivíduos entre 12 e 14 anos na condição de aprendiz. A partir de dezembro de 1998, com a aprovação da Emenda Constitucional $\mathrm{n}^{\circ}$ 20, a idade mínima passa a ser 16 anos, salvo na condição de aprendiz entre 14 e 16 anos de idade.

Ainda a respeito da legislação brasileira, em 1999 foi aprovado o decreto legislativo $\mathrm{n}^{\circ}$. 179, que "aprova os textos da Convenção 138 e da Recomendação 146 da OIT sobre a Idade Mínima de Admissão ao Emprego, adotadas em junho de 1973, em Genebra”, visando reduzir a incidência de trabalhadores adolescentes.

Observando os dados das PNADs, nota-se que o número de trabalhadores de 14 e 15 anos do sexo masculino, em todo o Brasil, passou de 1,354 milhões ( $42 \%$ dos meninos nessa faixa etária) em 1995 para 814 mil (25\%) em 2003, e entre as meninas foi de 709 mil (23\%) em 1995 para 385 mil (13\%) em 2003.

Sendo assim, questiona-se até que ponto as leis proibitivas, que são o principal instrumento utilizado pelos governos para a erradicação do trabalho infantil, são realmente efetivas. O presente estudo tem por objetivo, então, verificar os efeitos do aumento da idade mínima legal de ingresso no mercado de trabalho no Brasil para os adolescentes de 14 e 15 anos de idade.

Para analisar a questão o presente trabalho conta com mais quatro seções. Na próxima seção será apresentado um modelo econômico para o trabalho infantil, bem como os dados que serão utilizados. A terceira e quarta seções tratam, respectivamente, da análise descritiva e da análise econométrica. Finalmente, na quinta seção estão as principais conclusões. 


\section{Modelo econômico e base de dados}

\subsection{O Modelo Econômico do Trabalho Infantil}

De acordo com a teoria neoclássica, a decisão de oferta de trabalho se dá num contexto de maximização de utilidade. Segundo Berndt (1991), toma-se como argumentos da função utilidade a quantidade de bens que os indivíduos gostariam de consumir e a quantidade de horas de lazer que gostariam de desfrutar, e considera-se uma restrição orçamentária que é função da renda do não-trabalho, do tempo disponível e dos preços, tanto de bens quanto de lazer. Nesse contexto, o salário de reserva será um importante determinante de entrada ou não no mercado de trabalho: o indivíduo participará da força de trabalho quando o salário de mercado for maior que seu salário de reserva.

Então se pode dizer que, teoricamente, a restrição da participação na força de trabalho por adolescentes de 14 e 15 anos a partir da legislação altera a estrutura de mercado de duas maneiras: (i) deslocando a curva de demanda por trabalho para baixo, já que agora existe um "risco" ao contratar essas crianças; (ii) diminuindo a quantidade de trabalho ofertada, uma vez que somente aqueles que trabalham por um salário menor são contratados. No entanto, no caso de crianças e adolescentes a decisão de ingresso no mercado de trabalho não se dá como no caso de adultos - é uma decisão tomada pela família e não pelo indivíduo.

Inúmeros trabalhos já foram feitos para descrever e entender o que leva as famílias a inserirem suas crianças e adolescentes no mercado de trabalho, quando estas têm ainda a opção do estudo. Geralmente, considera-se que os pais são altruístas em relação aos filhos, e a decisão de inseri-los no mercado de trabalho apenas se daria num contexto em que a sobrevivência da família estivesse ameaçada. Assim, principalmente a pobreza, seguida da educação dos pais, da baixa atratividade da escola, de componentes culturais e outros aspectos de background familiar, como o tamanho da família, aparecem na literatura como os principais determinantes do trabalho infantil, pelo lado da oferta (Basu \& Van, 1998; Kassouf, 2001; Basu, 1999; Nielsen \& Dubey, 2001).

A maior parte desses trabalhos baseia-se no modelo formulado por Basu \& Van (1998), que mostraram o equilíbrio no mercado de trabalho 
com e sem a participação de crianças. Segundo os autores, a decisão de entrar no mercado de trabalho no caso de crianças é tomada pelos pais, considerando que cada família tem uma única função de utilidade.

Os resultados derivados do modelo estão baseados em pressuposições simples, representados essencialmente por dois axiomas, que por si só não garantem o equilíbrio múltiplo, mas permitem que ele ocorra. O primeiro deles é o Axioma da Luxúria, que significa que uma família apenas enviará a criança para o mercado de trabalho se disso depende sua sobrevivência, ou seja, se sua renda não proveniente do trabalho da criança for muito baixa. O segundo, o Axioma da Substituição, afirma que crianças e adultos são substitutos sob o ponto de vista das empresas. Os autores assumem ainda que existem $N$ famílias idênticas na economia.

O axioma da luxúria é utilizado para derivar a oferta de trabalho. Para derivar as funções de demanda utiliza-se o segundo axioma (da substituição), e assume-se que adultos e crianças são substitutos na produção, de acordo com uma escala adulto-equivalente denominada $\gamma$, sendo que $0<\gamma<1^{3}$. Pressupõe-se também que $n$ firmas idênticas produzem um único bem de consumo, e considera-se que as firmas são tomadoras de preço no mercado de fatores. Por meio das soluções encontradas, cada firma apresentará comportamento otimizador quando sua receita marginal for igual ao seu custo marginal, e, admitindo o axioma da substituição, escolherá o fator de produção que representa o menor custo possível (com menor preço).

De acordo com o modelo proposto, existirão dois equilíbrios estáveis: um com altos salários e sem trabalho infantil (superior), outro com baixos salários e crianças trabalhando (inferior). Os autores destacam que o nível de atividade econômica é importante para explicar a existência de trabalho infantil no modelo, pois se o nível de atividade é baixo e, conseqüentemente, a demanda por trabalho é pequena, haverá equilíbrio com salários baixos e crianças trabalhando; por outro lado, se a demanda por trabalho for elevada, haverá apenas o equilíbrio superior.

Basu e Van (1988), discutem ainda que, se existem múltiplos equilíbrios, banir o trabalho infantil pode fazer a economia passar do equilíbrio

\footnotetext{
${ }^{3}$ Assim, salários de adultos e crianças são equivalentes quando $w_{A}=w_{C} / \gamma$, onde $w_{A}$ é o salário do adulto e $w_{C}$ o das crianças, ambos exógenos.
} 
inferior para o superior, e uma vez no equilíbrio superior a proibição torna-se desnecessária, pois o equilíbrio é estável.

Além disso, é necessário que a proibição do trabalho infantil seja acompanhada de uma expansão no mercado de trabalho dos adultos, uma vez que se a renda dos adultos da família não aumentar o suficiente para garantir o sustento de seus membros, crianças e adolescentes poderão ser enviados ao mercado de trabalho, ou seja, a lei não será obedecida, ou a situação dos menores poderá ser ainda pior devido ao aumento da pobreza.

\subsection{Os Dados}

Serão utilizados os dados da Pesquisa Nacional por Amostra de Domicílios (PNAD) do Instituto Brasileiro de Geografia e Estatística (IBGE) dos anos de 1995 a 1999 e de 2001 a $2003^{4}$.

O sistema de pesquisas familiares (PNAD) foi implantado no Brasil a partir de 1967, com a finalidade de produzir informações básicas para o estudo do desenvolvimento sócio-econômico do País. Abrange a população residente nas unidades familiares, dividindo-se em duas partes: (i) pesquisa de caráter permanente, que são as características gerais da população, tais como educação, trabalho, rendimento e habitação e, (ii) pesquisa de caráter variável, tais como migração, saúde, nutrição e trabalho infantil entre outros. A pesquisa é feita anualmente excetuando os anos de censo, e realizada no ultimo trimestre do ano. Quanto à abrangência, a pesquisa é dividida em 5 grandes regiões sendo elas: sul, sudeste, centro-oeste, nordeste e norte, onde esta última refere-se somente à parcela urbana (exceção para o Tocantins, em que a pesquisa é realizada nas áreas urbana e rural).

A PNAD é realizada através de amostras probabilísticas de domicílios obtidas em três estágios de seleção: unidades primárias (municípios); unidades secundárias (setores censitários); e unidades terciárias (unidades domiciliares). O processo de expansão da amostra utiliza estimadores de razão cuja variável independente é a projeção da população residente, segundo tipo de área (região metropolitana e não metropolitana). Estas projeções consideram a evolução populacional ocorrida entre os censos (1980, 1991 e 2000), sob a hipótese de crescimento associado a taxas de fecundidade, mortalidade e migração.

\footnotetext{
${ }^{4}$ No ano 2000 a PNAD não foi efetuada em função da realização do Censo Demográfico.
} 
Os dados utilizados referem-se às pessoas com 14 e 15 anos no ano da pesquisa, incluindo características individuais e familiares, tais como idade, gênero, cor, se estuda, se trabalha, valor dos rendimentos, jornada de trabalho, idade e educação dos pais, região de moradia, situação de domicílio, etc. Os dados referentes à renda foram deflacionados pelo INPC - IBGE, divulgado pela Revista Conjuntura Econômica / FGV.

\section{Análise descritiva dos dados}

Por meio do Gráfico 1 nota-se que entre 1995 e 2003 houve declínio da proporção de meninos e meninas trabalhando, tanto na área urbana quanto na área rural. No entanto, apesar da redução significativa, a parcela de adolescentes que trabalham ainda é bastante elevada, principalmente na área rural.

No início do período analisado $74 \%$ dos meninos e $44 \%$ das meninas da área rural trabalhavam; na área urbana a proporção era menor: $32 \%$ dos meninos e $18 \%$ das meninas. Em 2003, cerca de cinco anos depois do aumento da idade mínima legal, $58 \%$ dos meninos e $27 \%$ das meninas da área rural trabalhavam, assim como $18 \%$ dos meninos e $11 \%$ das meninas da área urbana - o que representava cerca de 705 mil adolescentes na área urbana e 494 mil na área rural.

Gráfico 1. Proporção de meninos e meninas de 14 e 15 anos que trabalham,

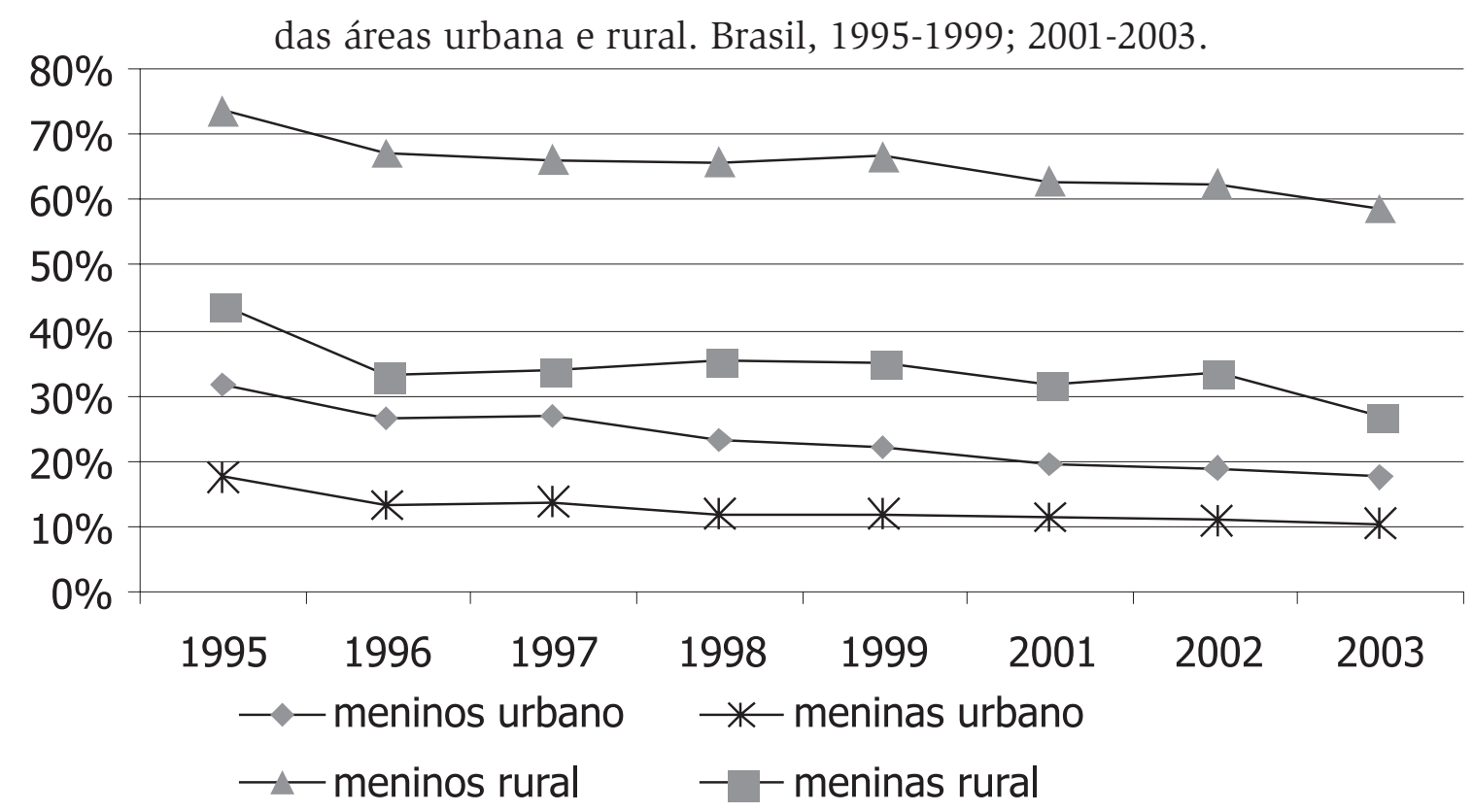

Fonte: PNAD-IBGE. 
A redução na proporção dos adolescentes que trabalham vem acompanhada do aumento no engajamento escolar desses indivíduos. Conforme pode ser observado no Gráfico 2, a proporção dos adolescentes que só estudam aumentou de $67 \%$ para $82 \%$ na área urbana e de $31 \%$ para $52 \%$ na área rural entre 1995 e 2003.

No mesmo período, na área urbana, houve um decréscimo na porcentagem dos que trabalham e estudam (de 18\% para 12\%) e dos que só trabalham (de $7 \%$ para $2 \%$ ), assim como a proporção dos que não trabalham nem estudam, que foi de $8 \%$ para $4 \%$. Já na área rural, a proporção dos que trabalham e estudam é bem mais elevada, e subiu de $32 \%$ para $38 \%$ entre 1995 e 2003, com picos de cerca de $42 \%$ entre 1999 e 2002. Observa-se ainda forte redução na proporção dos que apenas trabalham, que foi de $21 \%$ para $6 \%$. A proporção dos adolescentes da área rural que não estudam nem trabalham foi de $11 \%$ para 4\% entre 1995 e 2003 .

Analisando conjuntamente os Gráficos 1 e 2, percebe-se que, embora o movimento de redução do trabalho de adolescentes seja mais "suave" ao longo dos anos, não havendo variações bruscas inclusive no período imediatamente seguinte à aprovação das leis que restringem o trabalho nessa faixa etária, o aumento do engajamento escolar no mesmo período é mais acentuado, indicando que mesmo que os adolescentes não tenham deixado completamente as atividades laborais, incorporaram-se ao ensino formal.

Além disso, enquanto na área urbana a maior parte dos meninos e meninas com 14 e 15 anos só estuda, na área rural estudar e trabalhar tem mais importância entre as atividades dos adolescentes - pode-se dizer, numa análise bastante simplista e especulativa, que parte dos que somente trabalhavam passaram a trabalhar e estudar e parte estão somente estudando na área rural, enquanto na área urbana os que só trabalhavam estão apenas estudando.

O Gráfico 3 mostra a evolução da proporção de adolescentes de 14 e 15 anos segundo as atividades realizadas, dividindo a amostra por gênero. Nota-se que, entre 1995 e 2003, a proporção de meninos e meninas que só trabalham diminuiu de $15 \%$ e $7 \%$ para $4 \%$ e $2 \%$, respectivamente. É interessante notar que a diferença entre as proporções de meninos e meninas, que era de 8 pontos percentuais em 1995 foi reduzida para 2 pontos percentuais em 2003. 
A proporção dos que trabalham e estudam também é maior entre os meninos, embora a diferença tenha se mantido em 10 pontos percentuais. Meninos que trabalham e estudam representavam $26 \%$ dos adolescentes em 1995 e $21 \%$ em 2003, enquanto entre as meninas a proporção era de $16 \%$ e foi para $12 \%$ no mesmo período.

Gráfico 2. Proporção de adolescentes de 14 e 15 anos que só estudam, que trabalham e estudam, que só trabalham e que não trabalham nem estudam. Brasil, 1995-1999; 2001-2003.

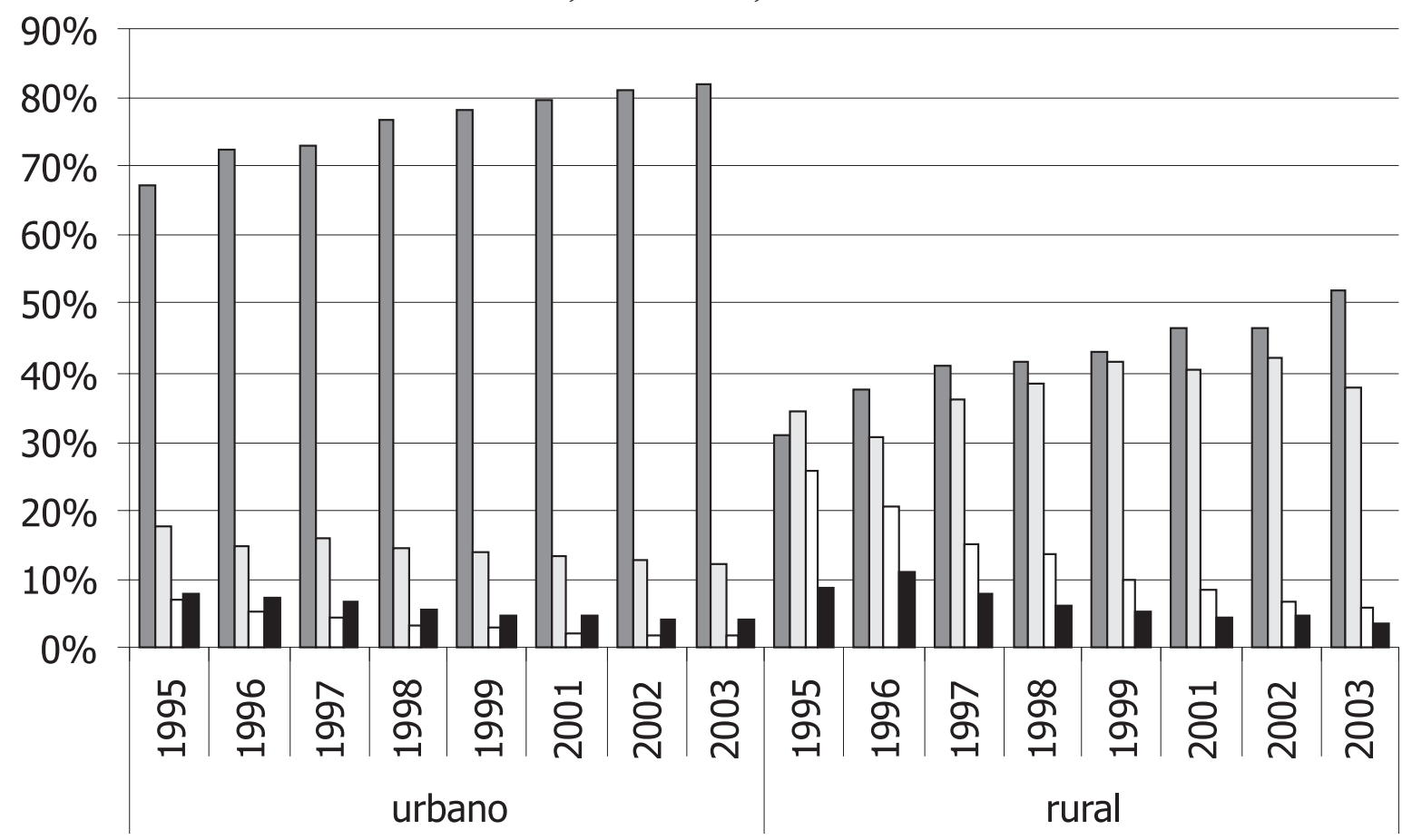

$\square$ só estuda $\square$ trabalha e estuda $\square$ só trabalha $\quad$ não trabalha nem estuda Fonte: PNAD-IBGE. 
Gráfico 3. Proporção de meninos e meninas de 14 e 15 anos que só trabalham, que trabalham e estudam, e que só estudam. Brasil, 1995-1999; 2001-2003.
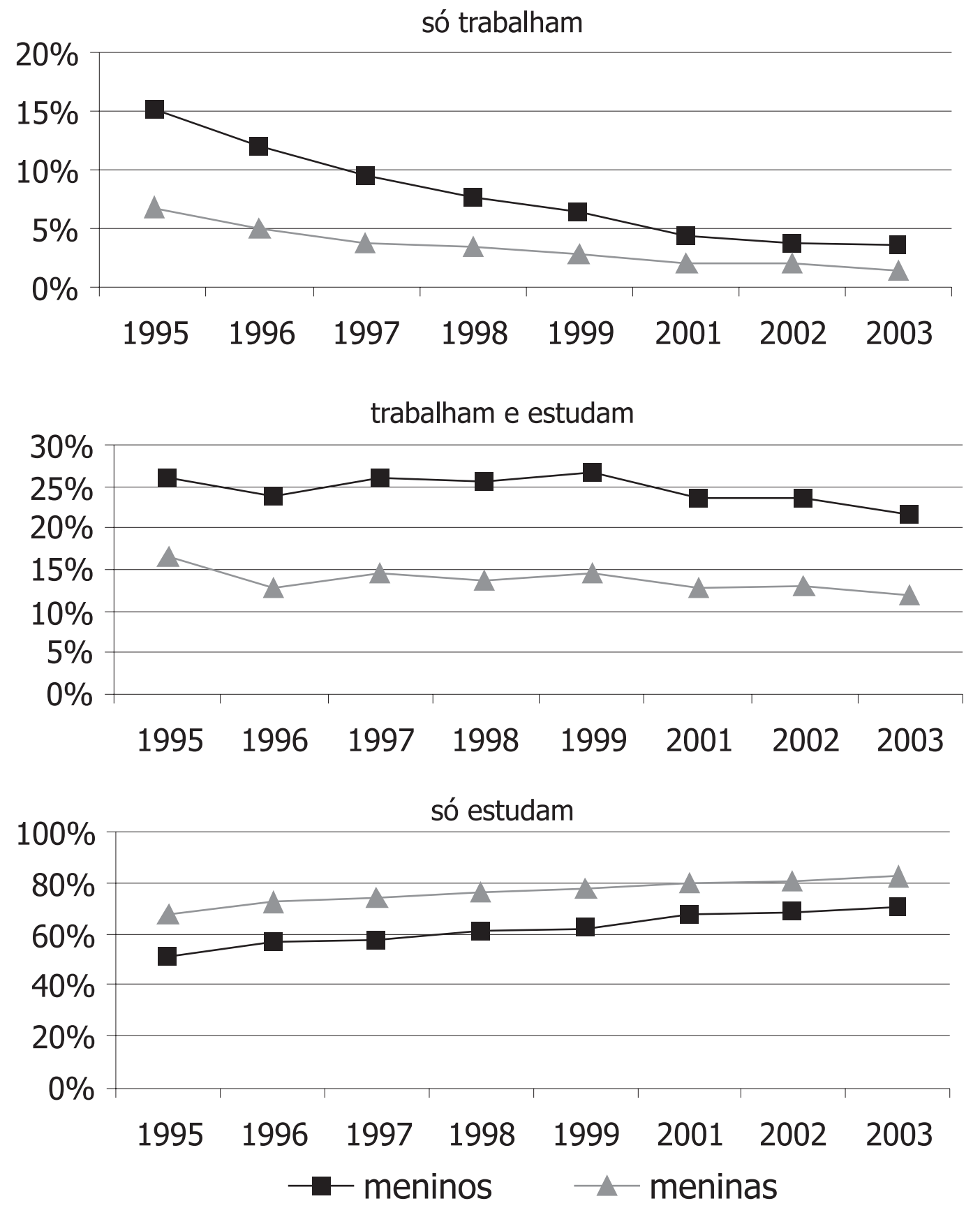

Fonte: PNAD-IBGE.

Em relação aos que só estudam, a proporção de meninos aumentou de $51 \%$ para $71 \%$ e a de meninas foi de $68 \%$ para $82 \%$, com leve redução na diferença entre meninos e meninas (de 17 para 11 pontos percentuais). Esses dados reforçam o fato de que meninas geralmente estudam mais do que os meninos, enquanto eles trabalham mais. 
Novamente, as informações sobre as atividades dos adolescentes ao longo dos anos não dão indicativos de que a legislação tenha contribuído muito para reduzir o trabalho desses indivíduos, uma vez que não há variações bruscas nas tendências apresentadas em nenhum período. Mesmo havendo reduções significativas, como é o caso da proporção de meninos que só trabalham apresentada no Gráfico 3, essa redução segue uma tendência clara desde o início do período, não evidenciando os efeitos da política.

A incidência de trabalho infantil é geralmente associada à pobreza, pois é uma forma de garantir a sobrevivência da família, embora existam outros fatores que influenciam a decisão da família de enviar seus filhos para o trabalho. O Gráfico 4 apresenta a evolução da renda per capita média real das famílias que têm entre seus membros meninos e meninas de 14 e 15 anos de idade, trabalhando ou não, nas áreas urbana e rural do Brasil, sem contar a renda do adolescente que trabalha.

$\mathrm{Na}$ área urbana, as famílias dos adolescentes que não trabalhavam em 1995 tinham renda per capita média de R $\$ 218$ por mês, enquanto as famílias dos que trabalhavam contavam com R $\$ 124$, sem contar com a renda do adolescente. Em 2003, essas famílias contavam com R \$ 153 e $\mathrm{R}$ \$ 102, respectivamente, descontada a inflação no período medida pelo INPC. Mesmo havendo redução na diferença de renda entre as famílias com adolescentes que trabalham e que não trabalham, aquelas ainda ganham mensalmente, por pessoa, cerca de $67 \%$ do que as famílias com adolescentes que não trabalham recebem.

$\mathrm{Na}$ área rural, por sua vez, a renda per capita familiar média de famílias com adolescentes que não trabalhavam era de R\$ 81 em 1995 enquanto a de famílias com adolescentes que trabalhavam era de R\$ 54. Em 2003, esses valores passaram para $\mathrm{R} \$ 68$ e R\$52. Nota-se que apesar dos aumentos reais na renda per capita familiar média mensal, tanto das famílias com adolescentes trabalhando quanto das com adolescentes que não trabalhavam, ocorridos entre 1996 e 1999, a partir de 2001 houve uma forte queda no poder de compra das famílias, retomando os níveis de 1995. Na área urbana, apesar de haver alguma elevação do poder de compra das famílias em 1998, o movimento é basicamente de queda na renda per capita real média. 
Gráfico 4. Renda per capita familiar média (em valores constantes) excluída a do adolescente, em famílias com adolescentes de 14 e 15 anos que trabalham e que não trabalham, das áreas urbana e rural. Brasil, 1995-1999; 2001-2003.

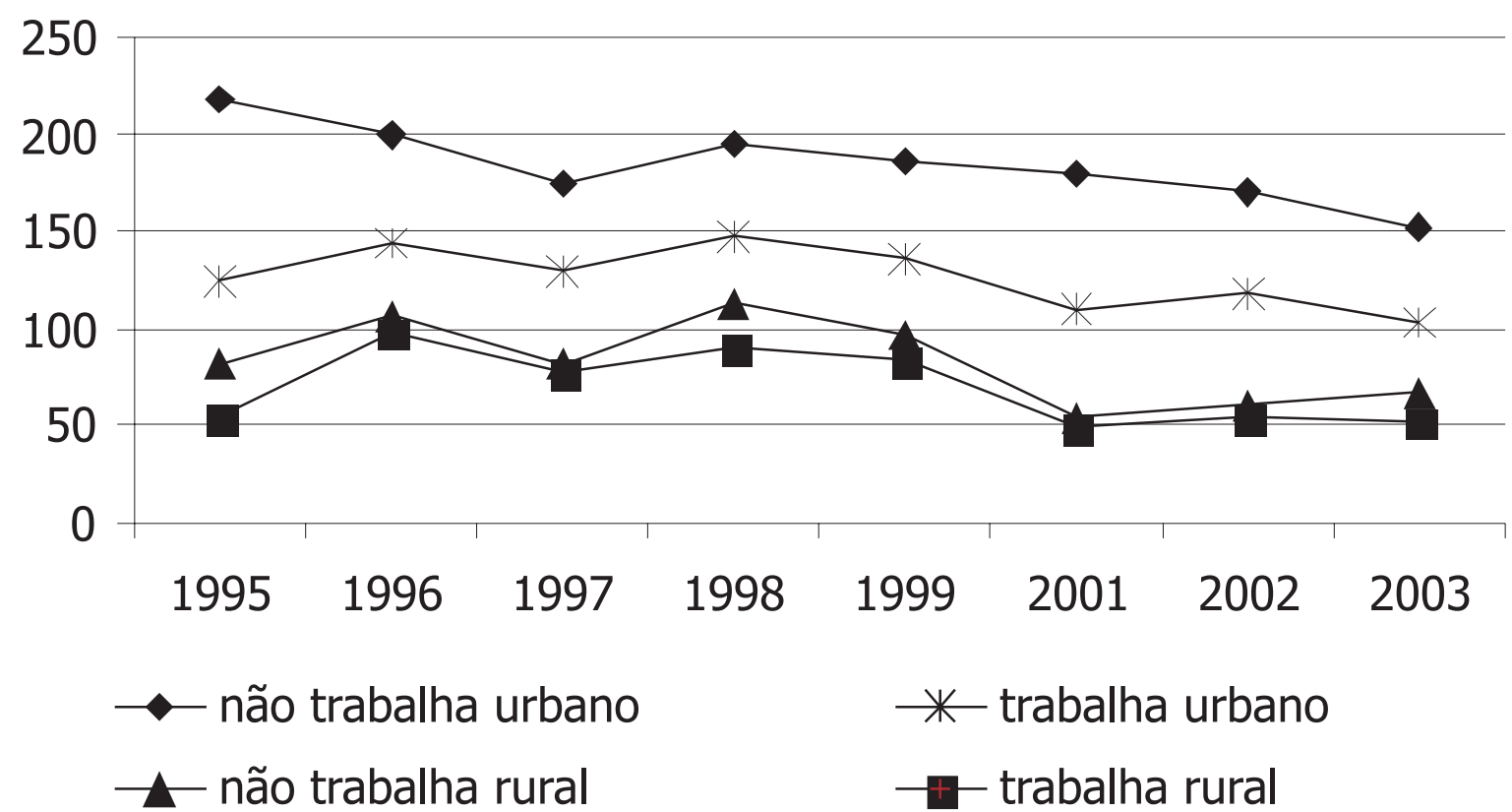

Fonte: PNAD-IBGE.

A queda do valor real da renda é mais evidente quando se trata dos salários médios mensais recebidos pelos adolescentes no período analisado, sendo mais acentuada entre os meninos e meninas da área urbana, que em 1995 ganhavam $\mathrm{R} \$ 104$ e R $\$ 90$ mensais, respectivamente, e em 2003 passaram a receber R 68 e R \$ 55, descontada a inflação (Gráfico 5). Entre os meninos e meninas da área rural, cujos salários passaram de $\mathrm{R} \$ 79$ e $\mathrm{R} \$ 70$ para $\mathrm{R} \$ 75$ e $\mathrm{R} \$ 42$, respectivamente, entre 1995 e 2003, a tendência de queda é mais suave, embora os salários sejam muito menores do que os da área urbana. ${ }^{5}$

A diferença entre os salários, bem como a queda menos acentuada no período entre os adolescentes da área rural, pode ser explicada pelo fato de a maioria dos postos de trabalho da área rural serem ocupados por pessoas menos qualificadas que os da área urbana, pelas próprias características do trabalho, fazendo com que os salários da área rural sejam menores, mesmo entre os adultos.

\footnotetext{
${ }^{5}$ Vale ressaltar que a maioria dos adolescentes que trabalham no meio rural não recebe rendimento (em torno de $70 \%$ ), enquanto que na área urbana a proporção dos sem renda cai para $30 \%$.
} 
Gráfico 5. Rendimento médio mensal do trabalho (deflacionado) de meninos e meninas de 14 e 15 anos que trabalham e recebem rendimento, das áreas urbana e rural. Brasil, 1995-1999; 2001-2003.

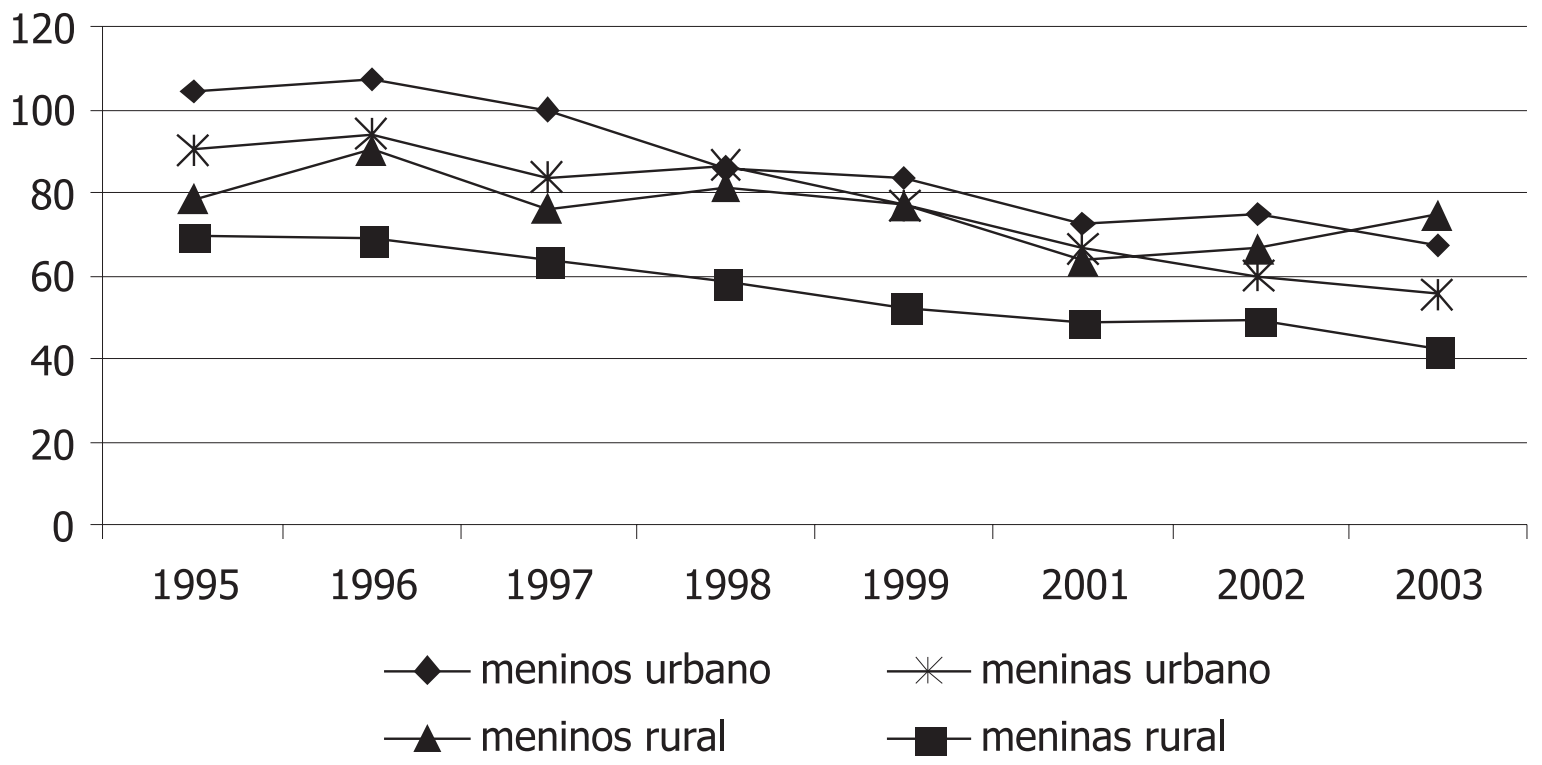

Fonte: PNAD-IBGE.

Além dos efeitos da inflação, a queda no salário real que os adolescentes recebem por seu trabalho pode ser efeito da proibição do ingresso para menores de 16 anos salvo na condição de aprendiz por, basicamente, duas razões: a deterioração dos postos de trabalho e a redução da carga horária.

No primeiro caso, o aumento da idade mínima legal para o trabalho faz com que haja um risco para os empregadores em contratar adolescentes sem a condição de aprendiz, uma vez que a fiscalização do trabalho pode multá-lo, a firma pode sofrer processos, etc. Nesse caso, serão contratados somente aqueles adolescentes que se sujeitam a piores condições de trabalho (mercado informal) para que a subsistência da família seja garantida, fazendo com que, na média, os salários se reduzam.

Considerando o trabalho "formal" como empregado com carteira, trabalhador doméstico com carteira e conta-própria ${ }^{6}$, pode ser visto no Gráfico 6 que a redução do emprego "formal" entre os adolescentes é maior na área urbana que na área rural. A evolução da proporção de trabalhadores "formais" mostra que essa proporção apresenta queda modesta entre

'Não foram considerados "formais": outros empregados sem carteira, trabalhador doméstico sem carteira, trabalhadores domésticos e empregados sem declaração de carteira, trabalhador na produção para o próprio consumo e na construção para o próprio uso e os não remunerados. 
1995 e 2003 na área rural tanto em relação aos meninos (de 5\% para 3\%) quanto em relação às meninas (de $7 \%$ para $5 \%$ ). Na área urbana há uma variação grande entre os meninos com emprego formal que representavam $25 \%$ dos adolescentes que trabalhavam em 1995, caindo para $13 \%$ em 2003 , enquanto as meninas passam de $15 \%$ para $11 \%$.

Gráfico 6. Proporção de meninos e meninas de 14 e 15 anos com trabalho "formal”, das áreas urbana e rural. Brasil, 1995-1999; 2001-2003.

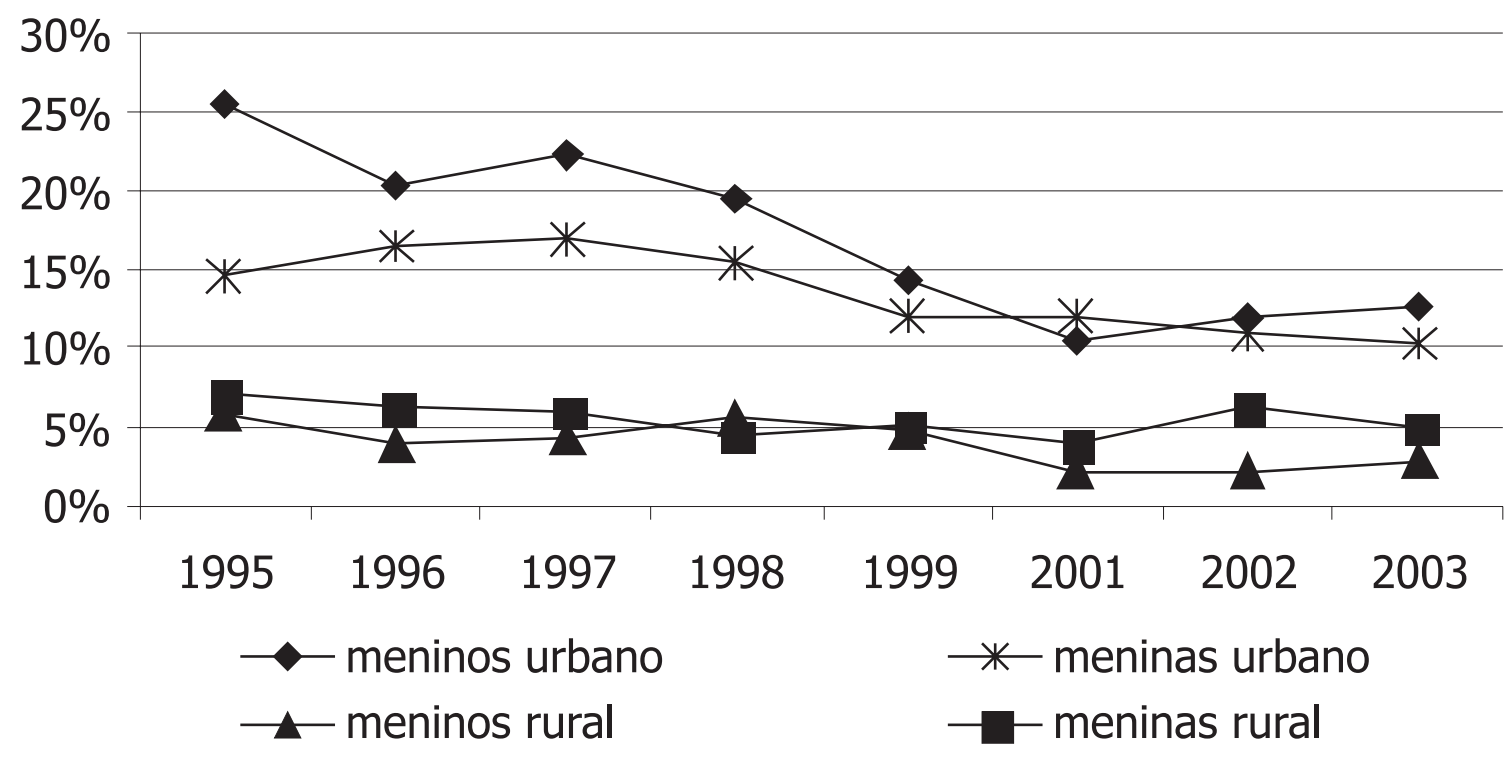

Fonte: PNAD-IBGE.

Em relação à carga horária, o Gráfico 7 mostra a redução na proporção dos meninos que trabalhavam mais de 40 horas semanais (de $50 \%$ para $25 \%$ ) entre 1995 e 2003 , e o aumento da porcentagem dos que trabalhavam entre 15 e 39 horas semanais de $43 \%$ para $50 \%$. A maior elevação foi da proporção dos que trabalhavam até 14 horas semanais, que foi de $7 \%$ para $17 \%$.

Entre as meninas, que em 1995 já trabalhavam predominantemente meio período, a proporção das que trabalhavam mais de 40 horas semanais sofreu redução de $41 \%$ para $20 \%$ e a das que trabalhavam entre 15 e 39 horas por semana foi aumentada de $44 \%$ para $54 \%$, assim como a porcentagem de meninas que trabalhavam até 14 horas, que foi de $15 \%$ para $25 \%$. 
Gráfico 7. Proporção de meninos e meninas de 14 e 15 anos que trabalham, segundo o grupo de horas semanais trabalhadas. Brasil, 1995-1999; 2001-2003.

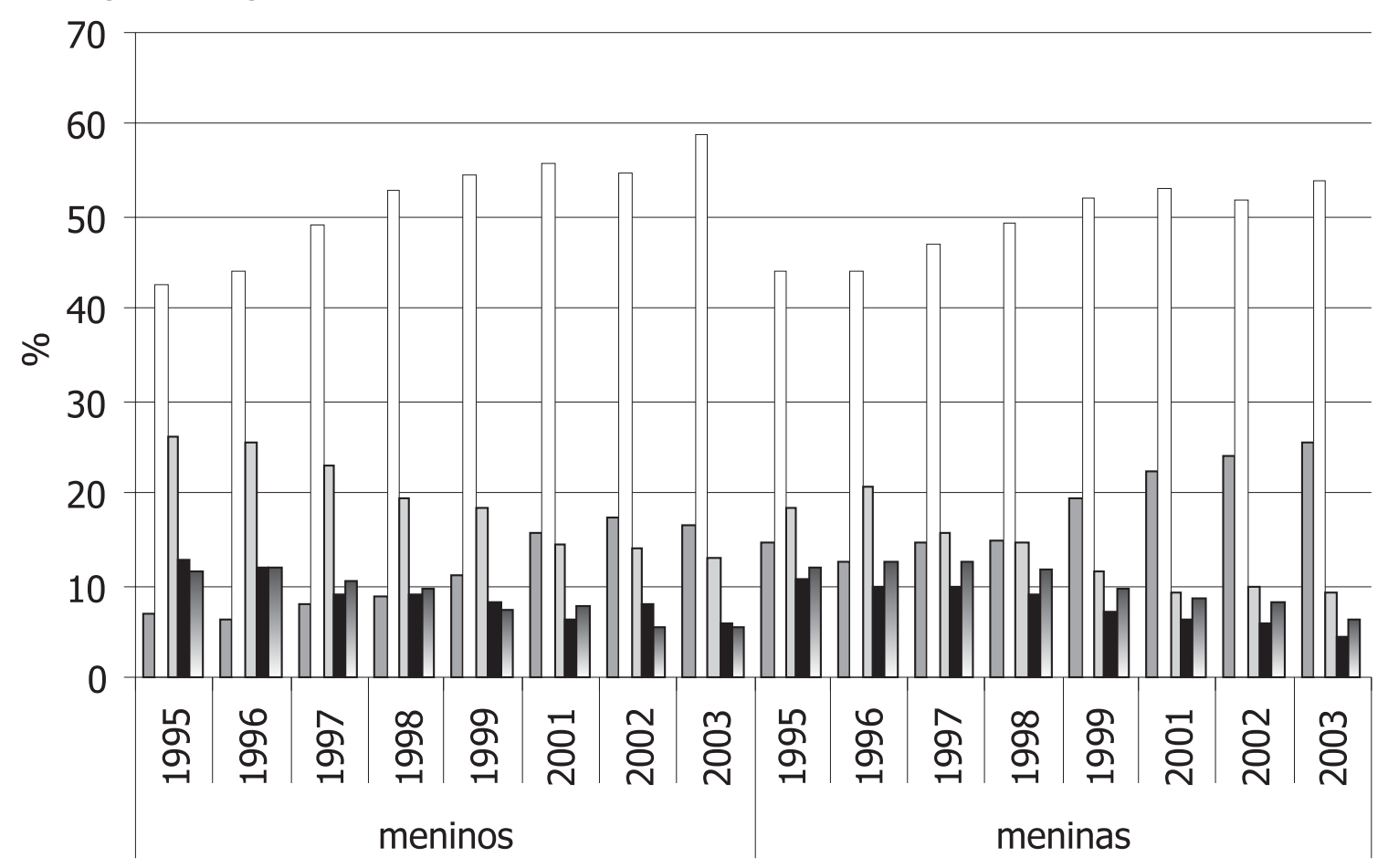

$\square$ até $14 \quad \square 15$ a $39 \quad \square 40$ a $44 \quad \square 45$ a $48 \quad \square 49$ ou mais

Fonte: PNAD-IBGE.

A análise de estatísticas descritivas dos dados é bastante útil para compreender as principais características dos adolescentes de 14 e 15 anos no que se refere à renda, ao trabalho e à educação e sua evolução ao longo do tempo, mas não permite isolar os efeitos da legislação na redução das taxas de participação no mercado de trabalho. Para isso, a próxima seção dedica-se à análise econométrica mais complexa dos dados das PNADs do período 1995-2003, excetuando-se o ano de 2000 em que foi realizado o Censo Demográfico.

\section{Análise econométrica}

\subsection{O modelo econométrico}

O objetivo deste estudo é obter o efeito da legislação que aumenta a idade mínima legal de ingresso no mercado de trabalho sobre a decisão de trabalhar dos adolescentes de 14 e 15 anos de idade. 
Nesse caso, a variável dependente é binária, assumindo o valor um para o adolescente que trabalha, e zero para o que não trabalha. Além disso, são utilizadas oito bases de dados cross-section para a estimação (1995-1999 e 2001-2003). Os dados são utilizados na forma de pooling, permitindo maior variabilidade e uma análise dos períodos anteriores e posteriores à mudança na legislação.

Pode-se então especificar o modelo para o indivíduo $i$ no período $t$ como:

$$
Y_{i t}^{*}=X_{i t}^{\prime} \beta+v_{i t}
$$

onde:

$$
\begin{aligned}
& Y_{i t}=1 \text { se } Y_{i t}^{*}>0 \\
& 0 \text { caso contrário }
\end{aligned}
$$

$Y^{*}$ é a propensão não-observável de o indivíduo trabalhar

$X$ é um vetor de variáveis exógenas

$\beta$ é o vetor de coeficientes associado ao vetor $X$

$v$ é o vetor de termos de erro não-observáveis

Logo, assume-se que a incidência de trabalho infantil é observada apenas quando a propensão de o indivíduo trabalhar é maior que zero.

Para tentar isolar o efeito da legislação, é incluída no vetor de variáveis $X$ a variável $L$ - período após a legislação - que tem o valor 1 para os anos subseqüentes à aprovação das leis (1999 e de 2001 a 2003) e zero para os anos anteriores (1995 a 1998).

Além da legislação, foram incluídas variáveis comumente encontradas na literatura a respeito do trabalho infantil, como características individuais (idade, cor e se estuda) familiares (renda familiar, número de irmãos, escolaridade e idade dos pais) e regionais.

Ademais, incluiu-se uma variável para tentar captar o efeito das políticas de combate à pobreza e ao trabalho infantil, implementadas em âmbito nacional a partir de 2000/2001, com os programas Bolsa-escola e Bolsa Alimentação, que atualmente compõem o programa Bolsa-Família, bem como o aumento da cobertura de outros programas de natureza similar que têm impacto na decisão de trabalho das crianças. A variável "programas sociais", dessa maneira, é uma variável binária com valor 1 para os jovens de famílias com renda per capita igual ou inferior a meio salário-mínimo nos anos de 2001 a 2003, sendo zero para os demais. 
Limitando-se a renda familiar, seleciona-se o grupo de pessoas elegíveis para o recebimento de ajuda governamental.

Finalmente, foram incluídas variáveis binárias para cada ano da amostra analisada a fim de captar a tendência de queda da porcentagem de crianças trabalhando, que se vem observando ao longo do tempo. Uma vez controlada a tendência de queda no trabalho infantil, consegue-se isolar melhor o efeito da legislação.

\subsection{Resultados e Discussão}

Foram estimadas equações separadas para meninos e meninas das áreas urbana e rural de todo o Brasil, e os efeitos marginais estão na Tabela 1. O coeficiente da variável de interesse - legislação - é estatisticamente significativo em todas as equações estimadas, apresentando o sinal esperado. A existência da legislação que aumenta a idade mínima de ingresso para 16 anos reduz em 7,4 e 3,4 pontos percentuais a probabilidade de meninos e meninas, respectivamente, com 14 ou 15 anos que moram na área urbana trabalhar. Nas equações da área rural a queda foi de $4 \%$ para os meninos e de $6 \%$ para as meninas.

Souza \& Chahad (2003) estimaram os efeitos da legislação sobre o trabalho infantil dos adolescentes. Utilizaram o método de diferenças em diferenças e os dados da PNAD de 1997 e 2001 e, sob a hipótese de que a única diferença entre o grupo de tratamento e o grupo de controle é a mudança na legislação, não encontraram evidências que esta tivesse efeitos sobre a redução do trabalho de adolescentes no período.

Moehling (1999), utilizando os dados dos censos de 1880, 1900 e 1910 dos Estados Unidos, procurou isolar os efeitos das leis estaduais proibindo o trabalho infantil de outras características que influenciavam a demanda e a oferta dessa mão de obra, também utilizando o método de diferenças em diferenças. Chegou à conclusão de que a imposição da idade mínima teve pouca influência na escolha ocupacional das crianças nesse período, e que tais restrições pouco contribuíram para reduzir o trabalho infantil no longo prazo.

Os efeitos marginais das variáveis de controle que representam as características individuais, familiares e regionais são, em sua maioria, significativos e apresentam o sinal esperado. Assim, o adolescente de 
14 anos de idade tem menor probabilidade de trabalhar do que o de 15 anos, e o mesmo acontece com aquele que freqüenta a escola em relação ao que não freqüenta.

Quanto às características da família, quanto maior a renda da família, menor é a probabilidade de o adolescente trabalhar. Aumentar em R\$ 100 a renda per capita média das famílias, o que exige um grande esforço para economia como um todo, reduz em 0,68 pontos percentuais a probabilidade de meninos que moram na área rural trabalharem e em cerca de 0,21 pontos a chance de meninas da área urbana estarem empregadas.

No caso de meninos e meninas da área urbana, quanto maior a idade e a educação (medida em anos de estudo completos) do pai e da mãe, menor é a chance de estarem trabalhando. Para os meninos e meninas da área rural, quanto mais educados o pai e a mãe menor é a probabilidade de trabalhar, mas quanto mais velha é a mãe essa probabilidade torna-se maior, sendo que o coeficiente da idade do pai não se mostrou significativo.

Ainda em relação às características familiares, quanto maior o número de irmãos com menos de 13 anos ou com 14 anos ou mais, maior é a chance de o adolescente ir para o mercado de trabalho, provavelmente para elevar a renda familiar frente a um aumento de demanda devido ao elevado número de membros da família. Para o caso de meninos na área urbana, entretanto, observa-se um coeficiente negativo para a variável que representa o número de irmãos mais velhos, mostrando que há uma substituição da mão-de-obra, em que irmãos mais velhos trabalham e permitem que os mais novos não trabalhem e, provavelmente, estudem. 


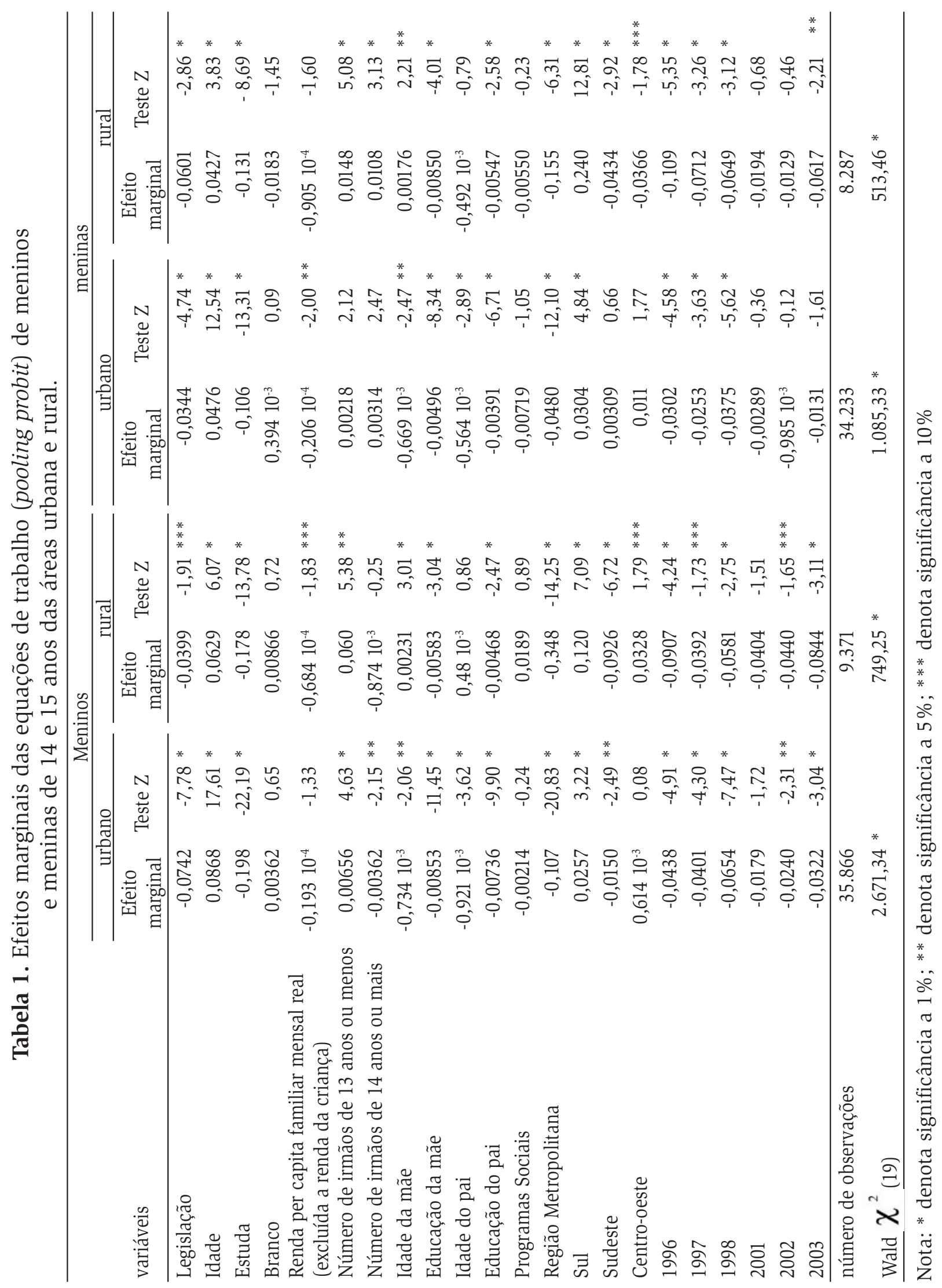


Entre as variáveis que controlam os efeitos regionais, morar nas regiões metropolitanas reduz a probabilidade de trabalho, e esse efeito é bastante significativo nas equações analisadas (10,7 e 4,8 pontos percentuais, para meninos e meninas da área urbana, respectivamente e 3,5 e 1,6 pontos percentuais, para meninos e meninas da área rural, respectivamente).

A variável de controle utilizada para tentar isolar o efeito das políticas sociais de incentivo ao engajamento escolar e/ou erradicação do trabalho infantil, cuja cobertura teve um importante salto quantitativo no início desta década - principalmente a partir de 2001, com a implementação em nível nacional do programa Bolsa-escola - não apresentou coeficiente significativo a $10 \%$ ou menos.

Como no presente estudo, em pesquisas em que o objetivo principal foi medir o impacto de programas como o Bolsa-escola sobre o trabalho de crianças e adolescentes, também não foi possível encontrar evidências de que este diminuísse a taxa de participação das crianças no mercado de trabalho, embora fosse eficiente em aumentar o engajamento escolar (Cardoso e Souza, 2003; Ferro e Kassouf, 2004).

As binárias representando os anos de análise dos dados (1995 foi omitido) apresentaram sinal negativo e significativo, evidenciando tendência de queda na porcentagem de adolescentes trabalhando. A variável que representa o ano de 1999 foi automaticamente excluída da equação por apresentar colinearidade.

\section{Conclusões}

Este trabalho verificou os efeitos que o aumento da idade mínima legal para ingresso no mercado de trabalho no Brasil tiveram na oferta de trabalho dos adolescentes de 14 e 15 anos de idade. De acordo com a Constituição de 1988, a idade mínima para ingresso no mercado de trabalho era de 14 anos, permitindo-se o ingresso de indivíduos entre 12 e 14 anos na condição de aprendiz. A partir de dezembro de 1998, com a aprovação da Emenda Constitucional n ${ }^{\circ}$ 20, a idade mínima passa a ser 16 anos, salvo na condição de aprendiz entre 14 e 16 anos de idade.

Foram realizadas análises de freqüência e econométrica mais complexa dos dados das PNADs entre 1995 e 1999 e entre 2001 e 2003. Nota-se que o número de trabalhadores do sexo masculino de 14 e 15 anos, em 
todo o Brasil, passou de 1,354 milhões ( $42 \%$ dos meninos nessa faixa etária) em 1995 para 814 mil (25\%) em 2003, e entre as meninas foi de 709 mil (23\%) em 1995 para 385 mil (13\%) em 2003.

Considerando meninos e meninas que só trabalham, que estudam e trabalham e que só estudam, observa-se a redução da proporção dos que só trabalham, com o aumento concomitante da proporção dos que só estudam e dos que estudam e trabalham.

No entanto, com base apenas na análise de freqüência dos dados não foi possível identificar os efeitos do aumento da idade mínima legal sobre os adolescentes, uma vez que as reduções na taxa de participação no mercado de trabalho, dos rendimentos e da proporção dos que trabalham menos de 40 horas semanais - assim como o aumento do engajamento escolar - não apresentaram nenhuma quebra notável na tendência entre 1998 e 1999. Parece que a evolução dessas variáveis é mais conseqüência de uma tendência natural do que resultado da legislação.

Para testar a hipótese de que o aumento da idade mínima para o trabalho para 16 anos exerceu alguma influência sobre a decisão de trabalho dos adolescentes de 14 e 15 anos, utilizou-se na análise econométrica um modelo probit agregando-se os dados disponíveis das PNADs de 1995 a 2003 (pooling). Os coeficientes da variável de interesse, que representa os anos em que a legislação estava em vigor, mostraram-se significativos para meninos e meninas com residência urbana e rural. Portanto, conclui-se que embora a legislação não tenha erradicado o trabalho infantil, ela contribuiu significativamente para reduzir a porcentagem de adolescentes no mercado de trabalho.

O método utilizado nesse estudo não permite distinguir os efeitos da variável de interesse dos efeitos de heterogeneidade individuais nãoobserváveis. Recomenda-se, então, para futuras pesquisas, a utilização de coortes como forma de se tentar controlar estes efeitos.

\section{Referências bibliográficas}

BASU, K. Child labor: cause, consequence, and cure, with remarks on international labor standards. Journal of Economic Literature, v.37, n.3, p.1083-1119, Sep. 1999. 
BASU, K.; VAN, P.H. Economics of child labor. The American Economic Review, v.88, n.3, p.412-427, June 1998.

BERNDT, E. The Practice of econometrics - classic and contemporary. Addison-Wesley Publishers, 1991.

BHALOTRA, S. Is Child Work Necessary? London School of Economics, Suntory Toyota, Development Economics Research Programme, Paper Series $n^{\circ}$ 26. 2001

BARROS, R. P., MENDONÇA, R. S. P., VELAZCO, T. A pobreza é a principal causa do trabalho infantil no Brasil urbano? Rio de Janeiro: DIPES/IPEA, 1994. Mimeo.

BRASIL. Leis, decretos, etc. Lei 8.069 de 13 de julho de 1990. http:// www.presidencia.gov.br/ccivil_03/Leis/L8069.htm (12 nov. 2003)

CARDOSO, E. SOUZA, A.P. The impact of income transfers on child labor and school attendance in Brazil. São Paulo: USP, 2003. http://www.econ. fea.usp.br/elianacardoso/ECONBRAS/cardoso-souza.pdf (22 out.

FERRO, A.R.; KASSOUF, A.L. Avaliação do impacto dos programas de bolsa escola sobre o trabalho infantil no Brasil. In: I Congresso da Associação Latino-Americana de População, Caxambu - MG. 2003. http://www. abep.org.br/usuario/Gerencia

Navegacao.php?caderno_id $=353 \&$ nivel $=1$ (02 março 2005)

GALLI, R. The economic impact of child labour. Genebra: ILO Decent Work Research Programme, 2001. 26p. (Discussion Paper, 128)

GREENE, W. Econometric Analysis, $3^{\circ}$ Edition, Prentice Hall, New Jersey, 1997.

GROOTAERT, C. Child labor in Cote d'Ivoire: incidence and determinants. The World Bank, Washington. 1998.

IBGE. "Pesquisa Nacional de Amostra por Domicílio". Rio de Janeiro, 1995. CD-Rom.

. "Pesquisa Nacional de Amostra por Domicílio". Rio de Janeiro, 1996. CD-Rom. 
_ _ "Pesquisa Nacional de Amostra por Domicílio”. Rio de Janeiro, 1997. CD-Rom.

- "Pesquisa Nacional de Amostra por Domicílio". Rio de Janeiro, 1998. CD-Rom.

. "Pesquisa Nacional de Amostra por Domicílio”. Rio de Janeiro, 1999. CD-Rom.

. “Pesquisa Nacional de Amostra por Domicílio”. Rio de Janeiro, 2001. CD-Rom.

__ .Pesquisa Nacional de Amostra por Domicílio”. Rio de Janeiro, 2002. CD-Rom.

. "Pesquisa Nacional de Amostra por Domicílio". Rio de Janeiro, 2003. CD-Rom.

JAFAREY, S., LAHIRI, S. Child Lador: Theory, Policy and Evidence. World Economics, 2001.

KASSOUF, A. L. Trabalho Infantil: Escolaridade x Emprego. Revista de Economia da Anpec. Campinas, v.2, n.2, p.549 - 586. 2001.

KASSOUF, A.L.; FERRO, A.R. O trabalho infantil no ramo agrícola brasileiro. Brasília: OIT, 2004. (série: Legado em transformação)

MOEHLING, C.M. State child labor laws and the decline of child labor. Explorations in Economic History, v.36, p. 76-106, 1999.

NIELSEN, H.S., DUBEY, A., 2001. "Child Labor: A Microeconomic Perspective," Papers 01-10, Aarhus School of Business - Department of Economics

SOUZA, A.P; CHAHAD, J.P.Z. Os direitos fundamentais dos trabalhadores, a cláusula social e comércio internacional: o caso do trabalho infantil no Brasil. In: Mercado de trabalho no Brasil: novas práticas trabalhistas, negociações coletivas e direitos fundamentais no trabalho. Org. José Paulo Z. Chahad e Maria C. Cacciamali. São Paulo: LTr, 2003.

WOOLDRIDGE, J.M. Econometric Analysis of Cross Section and Panel Data. Massachusetts: The MIT Press, 2001.

Recebido em janeiro de 2004 e revisto em fevereiro de 2005. 